\title{
La teoría de la banda miocárdica. Nuevos descubrimientos que apoyan el complejo mecanismo de torsión miocárdica
}

\author{
Jorge Trainini* \\ Vicente Mora Llabata** \\ Jorge Lowenstein***
}

\author{
Mario Beraudo**** \\ Mario Wernicke ${ }^{* * * *}$ \\ Alejandro Trainini*
}

\begin{tabular}{l} 
Correspondencia \\
Jorge Carlos Trainini \\
jctrainini@hotmail.com \\
\hline
\end{tabular}

* Departamento de Cirugía Cardíaca. Hospital Presidente Perón. Buenos Aires. Argentina

**Departamento de Cardiología. Hospital Dr Peset. Valencia. España

***Departamento de Cardiología. Investigaciones Médicas. Buenos Aires. Argentina

****Departamento de Cirugía Cardíaca. Clínica Güemes. Luján. Buenos Aires. Argentina

Recibido: 07/01/2020

Aceptado: 07/01/2020

En línea: 02/03/2020

Citar como: Trainini J, Mora Llabata V, Lowenstein J, Beraudo M, Wernicke M, Trainini A. La teoría de la banda miocárdica. Rev Ecocar Pract (RETIC). 2020 (Mar); 3 (1): 14-18. doi: 10.37615/retic.v3n1a4.

Cite this as: Trainini J, Mora Llabata V, Lowenstein J, Beraudo M, Wernicke M, Trainini A. The myocardial band theory. Rev Ecocar Pract (RETIC). 2020 (Mar); 3 (1): 14-18. doi: 10.37615/retic.v3n1a4.

\section{El corazón es una ciudad majestuosa de fronteras conocida con sus calles ocultas, misteriosas e inexploradas.}

\section{Hipótesis}

La función del corazón es de una dimensión mecánica que debe indagarse en los términos de su estructura. En la apreciación de su anatomía se halla el principio de la reflexión que llevó a investigaciones que explicasen su integridad organicofuncional. Si se hace una parada en las descripciones clásicas, se verá que la atención anatómica se prestó a sus superficies externa e interna, con muy poca importancia a la conformación muscular íntima. Se determinó de carácter homogéneo y sólido, con una contracción global uniforme y se soslayó que su capacidad mecánica exigía una reinterpretación de su anatomía espacial y de sus movimientos.

Si bien RF Shaner, en 1923, relata que "el miocardio está constituido por dos músculos aplanados en forma de 8 [y que] dichos músculos se enrollan en dirección opuesta en sístole, vaciando su contenido"1), fue Francisco Torrent Guasp (2), a partir de 1970, quien pudo describir e interpretar la banda muscular cardíaca, punto de partida de la comprensión de sus movimientos, demostrando en múltiples disecciones que el miocardio ventricular está constituido por un conjunto de fibras musculares retorcidas sobre sí mismas asemejando una cuerda, aplanada lateralmente a modo de una banda, que al dar dos vueltas en espiral define un helicoide que delimita los dos ventrículos y conforma su funcionalidad.

Una explicación para esta homogeneización muscular, que disimula a la banda miocárdica, mostrando al corazón como una masa íntegra, implica considerar que su solidez estructural se halla requerida en las aves y mamíferos para lograr que la sangre se eyecte a una velocidad alta en un tiempo acotado, por un órgano que debe abastecer dos circulaciones (sistémica y pulmonar). Actualmente, la banda muscular puede confirmarse por la investigación anatómica del corazón, la exploración histológica, las imágenes obtenidas con resonancia magnética por tensor de difusión, el análisis ecocardiográfico y con los estu- dios electrofisiológicos llevados a cabo con el mapeo electroanatómico tridimensional(3-7).

La disección muestra una estructura con planos definidos que permite los movimientos fisiológicos sucesivos y concatenados de estrechamiento, acortamiento-torsión, alargamiento-detorsión y ensanchamiento, dependientes de la propagación del estímulo eléctrico por los trayectos musculares de la banda cardíaca (Figura 1 y Figura 2).

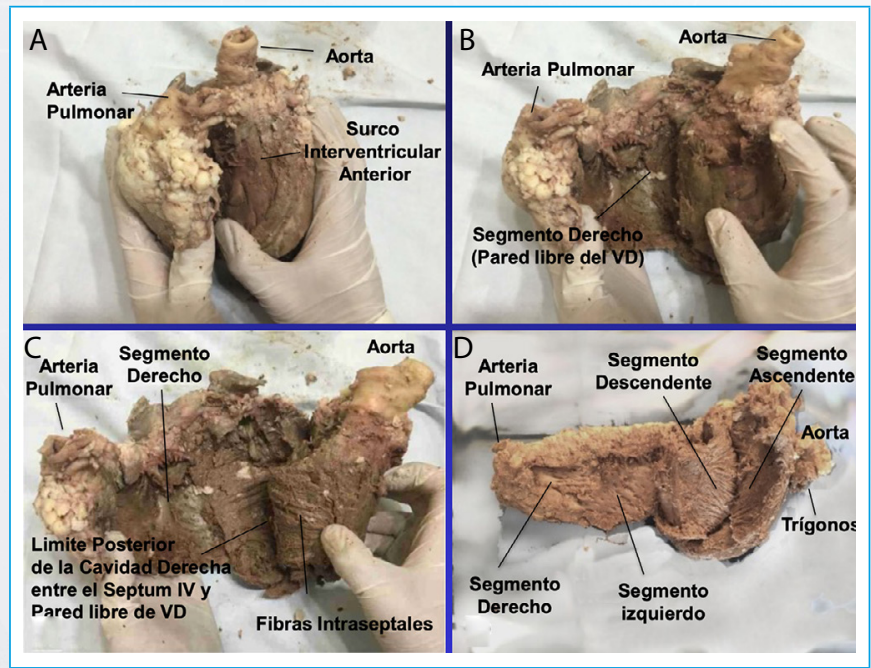

Figura 1. Desenrollamiento de la banda muscular (A-D)

La situación evolutiva y anatómica del corazón tiene correspondencia con la mecánica ventricular, pero adolecía de la comprensión de una propagación eléctrica que lo explicase con correlación a la fisiología. Los estudios emprendidos en este ámbito apuntan a demostrar la integridad de una estructurafunción cardíaca de carácter imprescindible. La activación eléctrica endocárdica y epicárdica del ventrículo izquierdo, mediante el mapeo electroanatómico tridimensional que se ha realizado en pacientes, permitió abordar este tema 
trascendental para analizarlo. El tubo circulatorio de los anélidos funciona en su progresión contráctil con un mecanismo de peristalsis. La propulsión a su largo conserva el patrón de la transmisión axial, pero tras el doblez que sufre el tubo cardíaco en los mamíferos y en las aves, se agrega la transmisión radial del impulso que permite un movimiento de hélix indispensable para producir los movimientos concatenados de torsión-acortamiento en la sístole y de detorsión-alargamiento en la fase de succión subsiguiente ${ }^{(7)}$.

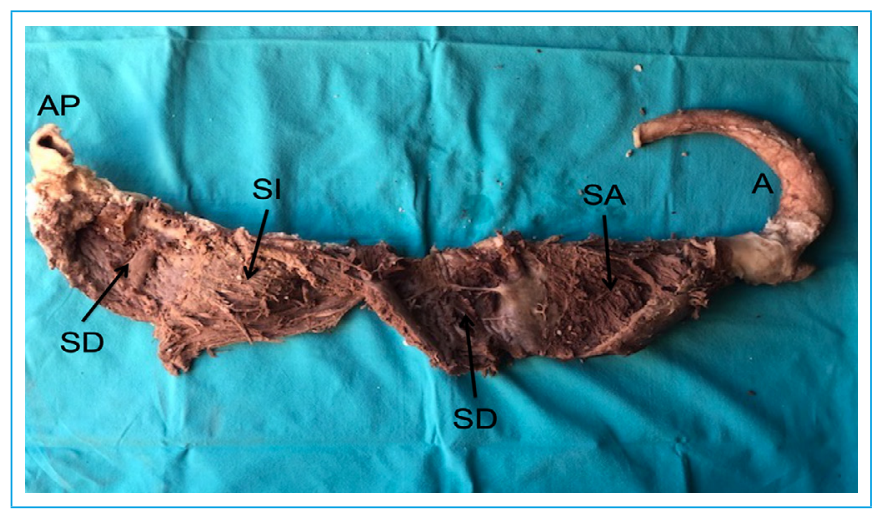

Figura 2. Banda desplegada en toda su extensión (AP: arteria pulmonar; SD: segmento derecho; SI: segmento izquierdo; SD: segmento descendente; SA: segmento ascendente; $\mathrm{A}$ : aorta)

Este camino, que lleva de estructura a función, conduce a tópicos poco explicados, a saber:

1. Investigación anatómica e histológica de la secuencia segmentaria de la banda miocárdica.

2. Apoyo e inserción de la banda miocárdica, ya que para retorcerse las bandeletas que rodean a los ventrículos deberían efectuarlo sobre un punto de apoyo al igual que un músculo lo hace en una inserción firme... ¿Los hay en el corazón?, ¿si es real este apoyo, cómo se inserta el músculo de la banda miocárdica en dicha estructura?

3. La torsión miocárdica representa la solución funcional para eyectar el contenido ventricular con la energía necesaria con el fin de irrigar todo el organismo. Esta situación se encuentra implícita en el estudio abordado de la activación ventricular para poder investigar cómo se produce la torsión miocárdica.

4. Fricción muscular. El deslizamiento de los segmentos de la banda, entre ellos, al efectuar la torsión-detorsión miocárdica, implica que debería existir un mecanismo antifricción que evite disipar la energía que emplea el corazón. ¿Hay una histología que explique este hecho?, ¿los conductillos venosos de Thebesius y Langer juegan algún papel en este mecanismo?, ¿existe un recurso lubricante orgánico?

5. La producción del vórtice intraventricular, estudiado por diversas técnicas de imágenes, es consecuencia del movimiento de torsión y de la necesidad del impulso que necesita el fluido sanguíneo para eyectarse. La teoría física de las estructuras disipativas explica actualmente la producción de este torbellino intraventricular.

6. Succión ventricular protodiastólica activa. Una fase de llenado cardíaco pasivo sería inviable por la pequeña diferencia de presión con la periferia. El llenado ventricular se investigó como un fenómeno activo con gasto de energía generado por una contracción miocárdica que tiende a alargar la distancia base-ápex del ventrículo izquierdo tras la fase de eyección, produciendo un efecto de succión por una acción similar al de una "ventosa". ¿Este mecanismo se explicaría por la contracción de las fibras más epicárdicas del segmento ascendente durante la fase isovolumétrica diastólica?

7. Restaurar la presión negativa suficiente en una cardiopatía para generar la succión ventricular izquierda y atraer la sangre de forma adecuada podría conseguirse con la resincronización cardíaca, siempre que la estimulación consiga realizarse en el lugar adecuado de la pared miocárdica.
8. Como resultado de estos dos últimos puntos: ¿debe considerarse en el corazón una fase de acople entre sístole y diástole en donde se produce la succión cardíaca?

9. En este corazón de "tres tiempos" (sístole, succión y diástole): ¿cómo es el mecanismo energético en la fase activa de succión?

Los métodos utilizados para explicar esta hipótesis de investigación consistieron en:

- La disección cardíaca en especímenes de bóvidos y humanos.

- El análisis histológico e histoquímico de las muestras anatómicas.

- La activación eléctrica endocárdica y epicárdica del ventrículo izquierdo en seres humanos mediante el mapeo electroanatómico tridimensional.

- La investigación sobre la succión ventricular izquierda en animales a quienes se les excluyó el ventrículo derecho.

- La medición de la presión intraventricular izquierda en la terapéutica de resincronización ventricular.

- La analogía de la función cardíaca con estrategias establecidas en la terapéutica médica habitual y la reinterpretación de las mismas (cirugía de bypass del ventrículo derecho, miocardioplastias, técnicas de contención ventricular, resincronización cardíaca y asistencia mecánica univentricular). - La ecografía de corroboración de lo investigado y del uso en la práctica clínica.

\section{Demostración}

La conformación helicoidal de la banda miocárdica tiene correspondencia con la función mecánica evidenciada por los diferentes segmentos que la componen. En la secuencia del análisis histológico de la banda miocárdica desplegada se demuestra la orientación lineal de acuerdo a la continuidad segmentaria que tiene su conformación espacial con la banda plegada, tanto en la cara interna como en la externa.

El miocardio es un músculo estriado sincitial, cuyas fibras siguen una dirección principal, junto a sus conexiones laterales, dispuestas en láminas con un grosor de 4-6 miocitos para formar un haz muscular. Estos haces musculares adoptan una oblicuidad secuencial de endocardio a epicardio hasta alcanzar direcciones opuestas (Figura 3 y Figura 4). La contracción muscular en dos ejes del espacio (longitudinal y circunferencial), a modo de material biológico auxético, supone ineludiblemente el engrosamiento en el tercer eje (radial), por el principio de conservación de la masa. Si el miocardio sincitial se comportase como una malla ${ }^{(8)}$, durante la sístole debería contraer su volumen y, sin embargo, con cualquier técnica de imagen se comprueba el engrosamiento del mismo hacia la cavidad ventricular durante la sístole.

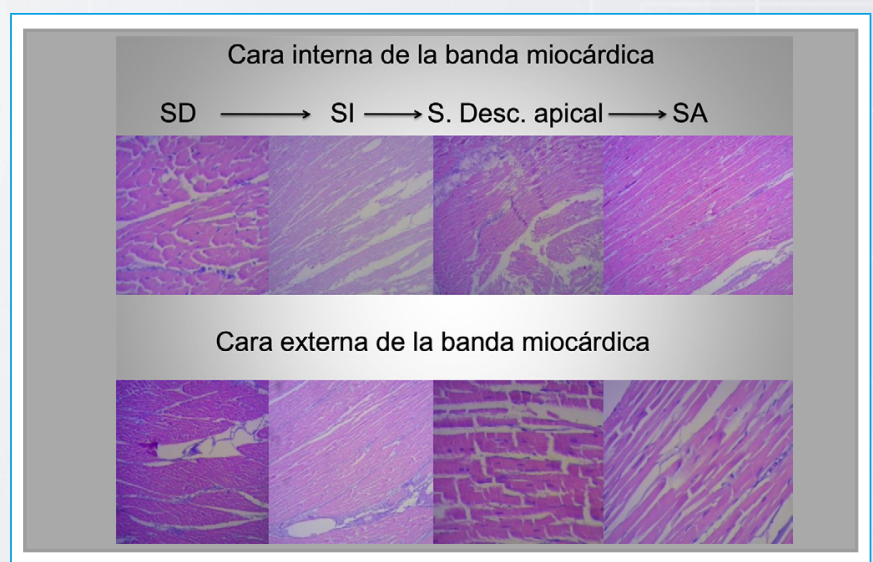

Figura 3. Secuencia segmentaria del análisis histológico de la banda miocárdica 


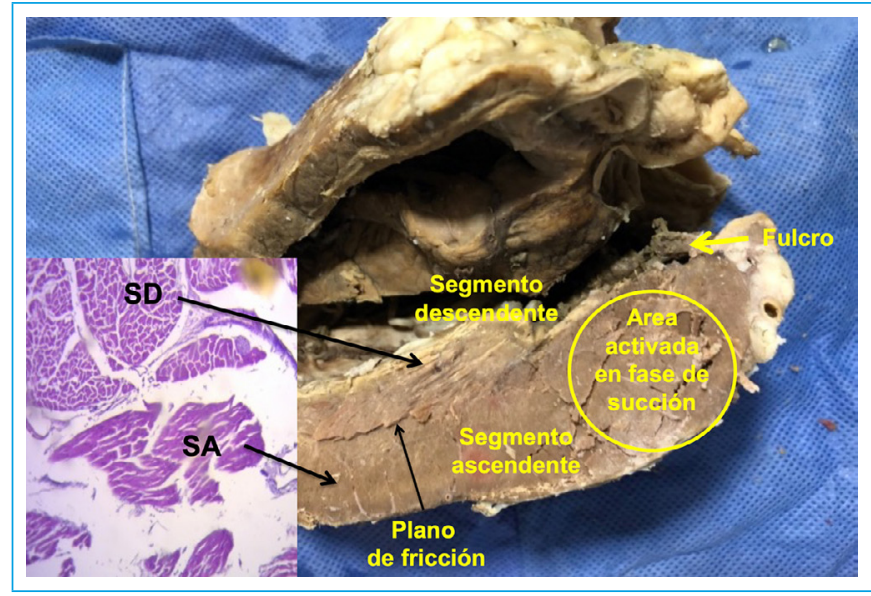

Figura 4. Sección longitudinal del ventrículo izquierdo. Se observa los segmentos descendente y ascendente adosados. El círculo señala la parte terminal del segmento ascendente, que discurre aislado para amarrarse al fulcro cardíaco. Este área se activa en la fase de succión cardíaca. En la histología se muestra la diferente orientación de las fibras longitudinales (segmento ascendente, SA) en relación al descendente (fibras transversales, SD) (corazón de bóvido)

La banda miocárdica no puede estar anatómicamente suspendida y libre en la cavidad torácica, dado que le sería imposible eyectar la sangre del corazón a una velocidad de $300 \mathrm{~cm} / \mathrm{s}$. Debía haber un sitio de amarre que, hallado, se denomina "fulcro cardíaco" (punto de apoyo de la palanca) (7) (Figura 5 a Figura 10).

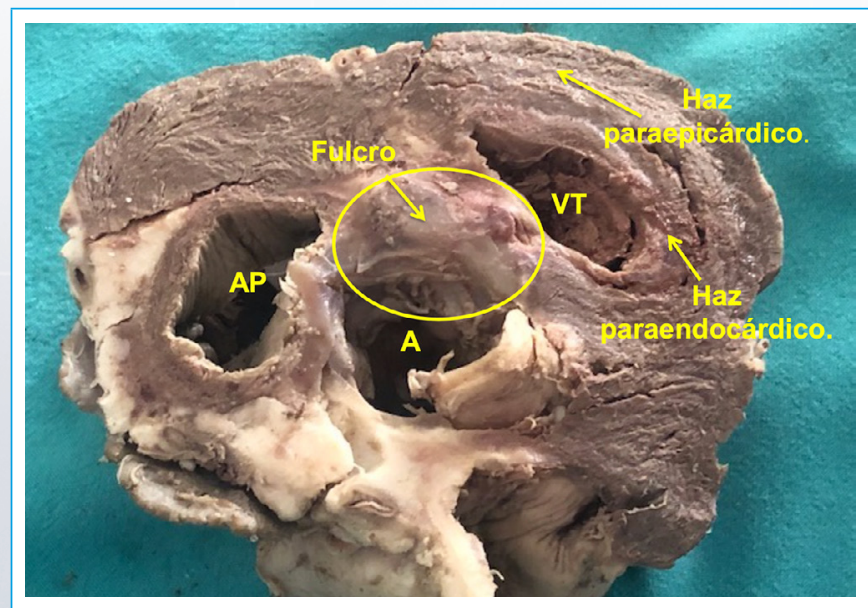

Figura 5. Fotografía aclaratoria de los haces musculares del segmento derecho que forma el ventrículo derecho que emergen del fulcro cardíaco (AP: arteria pulmonar; A: aorta; VT: válvula tricúspide) (corte transversal de un corazón bovino)

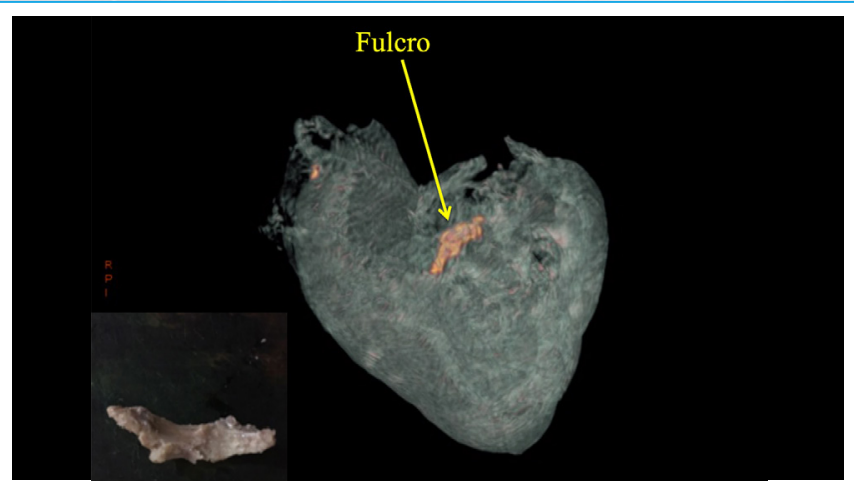

Figura 6. Se observa el fulcro cardíaco en tomografía computarizada (corazón bovino). Al pie se muestra el fulcro resecado



Figura 7. Técnica de hematoxilina y eosina a menor aumento (10x). Trabécula ósea madura que configura el tejido del fulcro cardíaco (corazón bovino)

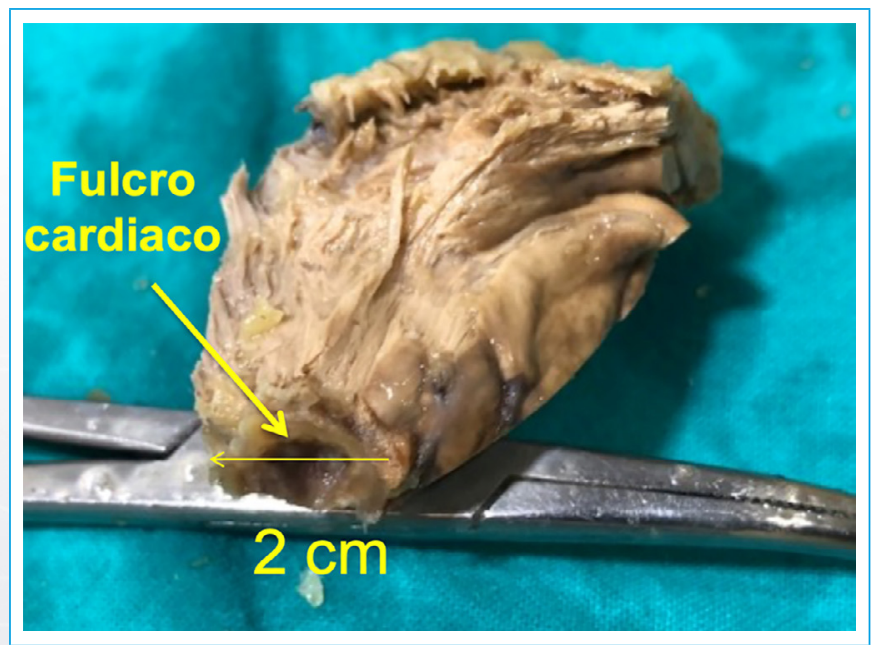

Figura 8. Fulcro cardíaco en un corazón humano de diez años de edad (explante)

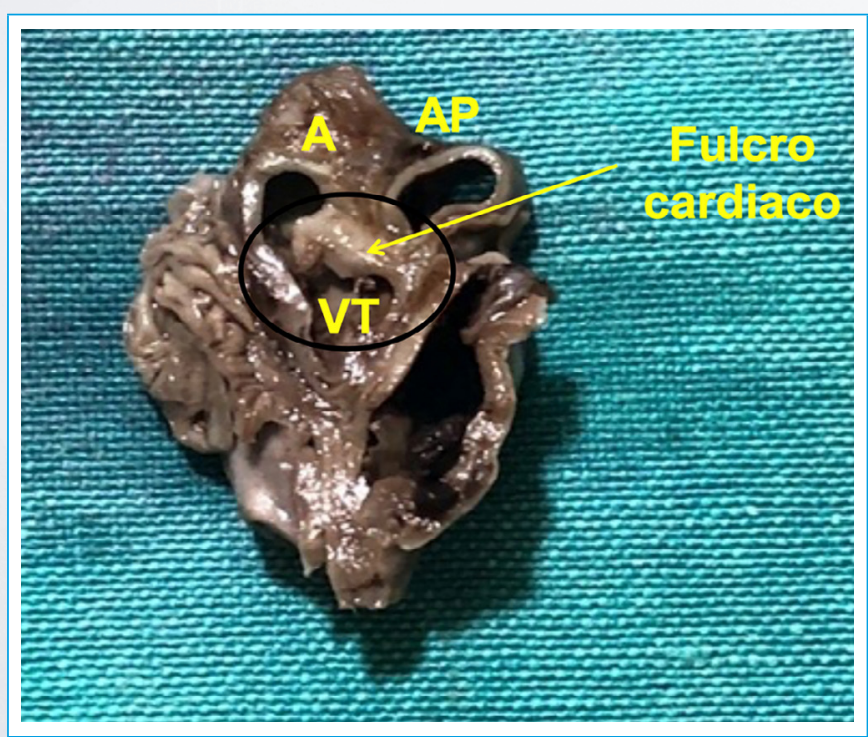

Figura 9. Fulcro cardíaco en corazón de embrión humano (23 semanas de gestación) (A: aorta; AP: arteria pulmonar; VT: válvula tricúspide) 




Figura 10. Fulcro resecado de un corazón humano adulto

En ese punto de apoyo las fibras musculares están obligadas inevitablemente a entramarse con el fulcro, que, de naturaleza conjuntiva, condroide u ósea, mostró en las investigaciones anatómicas e histológicas de los autores dicha inserción, sujetándose tanto al inicio como al fin de la banda miocárdica (Figura 11).

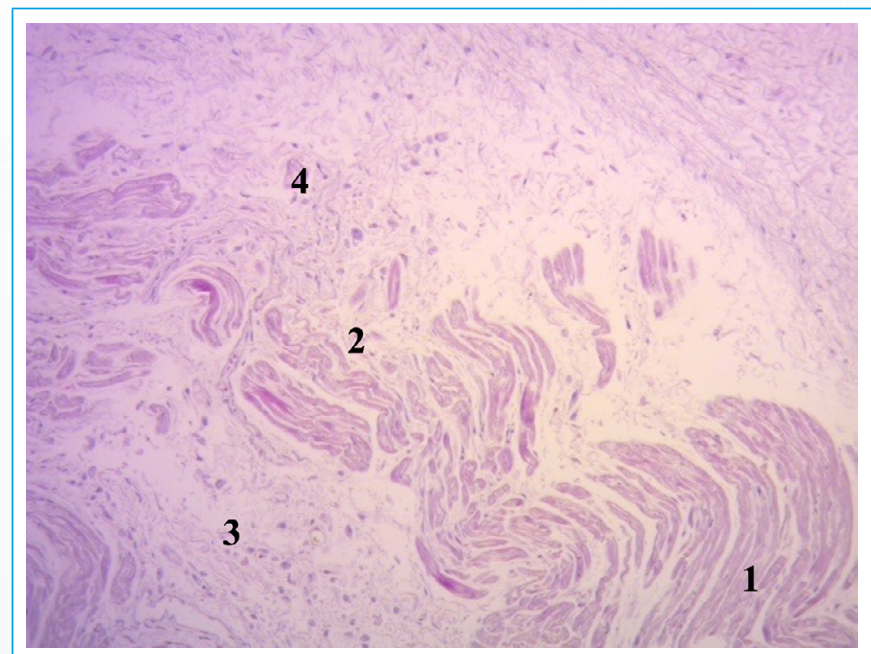

Figura 11. Miocardiocitos festoneados penetrando en matriz fibrocolágena (1: miocardiocitos festoneados; 2: deshilachamiento de miocardiocitos; $\mathbf{3 :}$ miocardiocitos atróficos; 4: matriz fibrocolágena) (corazón humano adulto)

Esta composición estructural guarda correspondencia con la activación de la banda. El estímulo corre de forma anisotrópica de endocardio a epicardio y a lo largo de sus trayectos musculares, pero para cumplir con la función que propone la disposición en hélice, tiene que accionar fundamentalmente los segmentos del ventrículo izquierdo, descendente y ascendente, con escasa diferencia temporal (Figura 12). La transmisión del estímulo entre ellos genera la torsión ventricular necesaria (situación similar a "estrujar una toalla").

La fase de succión del corazón no sería factible a través de una diferencia tan pequeña de presión con la periferia, y tampoco puede ser pasiva. La detorsión del corazón en los primeros 100 ms de la diástole (fase isovolumétrica diastólica) genera la fuerza intraventricular negativa para succionar la sangre en el ventrículo izquierdo, incluso en ausencia del ventrículo derecho, tal como se comprueba en experimentación animal. Esta fase de succión protodiastólica es activa, con gasto energético, provocada por la fase final de la contracción de las fibras ascendentes, ya con la válvula aórtica cerrada, lo que implica considerar que el corazón consta de tres tiempos: sístole, succión y diástole.

El deslizamiento contrapuesto de los segmentos internos endocárdicos del ventrículo izquierdo en relación a los subepicárdicos externos, con el fin de conseguir el mecanismo de torsión ventricular, generaría una ineludible fricción entre ellos. La progresiva oblicuidad de las fibras de endocardio a epicardio hasta alcanzar direcciones opuestas en los extremos hace que la fricción entre haces musculares quede reducida al mínimo. A ello contribuyen los conductillos venosos de Thebesius y Langer, con un sistema lubricante antifricción. En los estudios histológicos de esa trama esponjosa y sus conductillos se halló el efecto antifricción: ácido hialurónico, que transcurre por el espesor del miocardio (Figura 13).

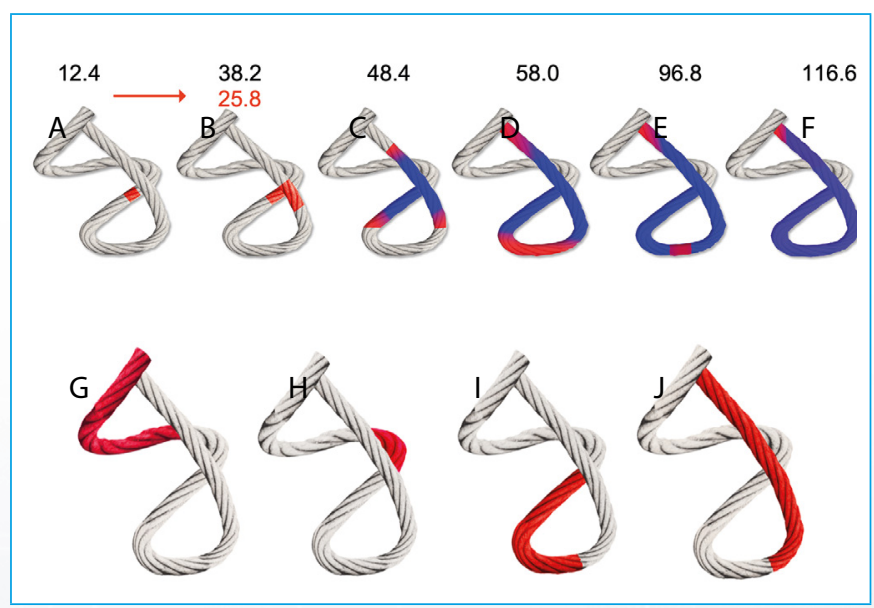

Figura 12. A: modelo de la cuerda: secuencia de activación (A-F) de la banda muscular según la investigación de los autores. Se observan los tiempos de propagación por la banda y el retardo radial entre las bandeletas en milisegundos (rojo: despolarización; azul: repolarización); B: modelo de la cuerda: propagación de la excitación (en rojo) de la banda muscular en forma unidireccional según teoría de Torrent Guasp (G-J)

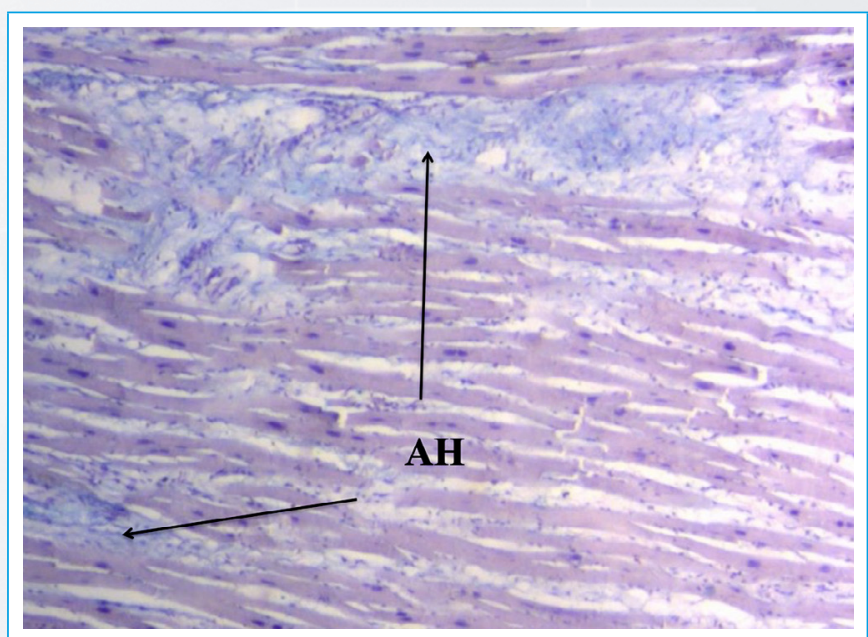

Figura 13. Intersticio entre miocardiocitos marcando el ácido hialurónico (AH) teñido de celeste con tinción de alcian blue (corazón humano adulto)

La disposición de la banda en forma helicoidal (estructura) y la torsión ventricular (función) conducen a que el contenido hemático intraventricular se vuelva un pequeño tornado, que se explica con las leyes físicas de las estructuras disipativas. 
El trabajo de Poveda et al. ${ }^{(9)}$ sobre la imagen tractográfica del corazón, obtenida por tensor de difusión a partir de la resonancia magnética, revela una disposición helicodal continua de las fibras miocárdicas de ambos ventrículos. En el laboratorio ecocardiográfico el estudio del strain (deformación) mediante la técnica de speckle tracking ha permitido reproducir los movimientos que simultáneamente se producen en el corazón como consecuencia de la orientación de las fibras cardíacas que componen la banda muscular. La interacción de la contracción longitudinal (fundamentalmente de origen subendocárdico) y circunferencial (fundamentalmente transmural-subepicárdica) de las fibras conduce al acortamiento del eje longitudinal ventricular, y la simultánea rotación en direcciones opuestas de la base y el ápex (torsión ventricular), cuyo resultado final es el engrosamiento radial del miocardio hacia la cavidad ventricular y la consiguiente eyección sanguínea durante la sístole. En realidad, son las mismas fibras que en su recorrido van tomando diferente disposición como puede apreciarse en la Figura 14.

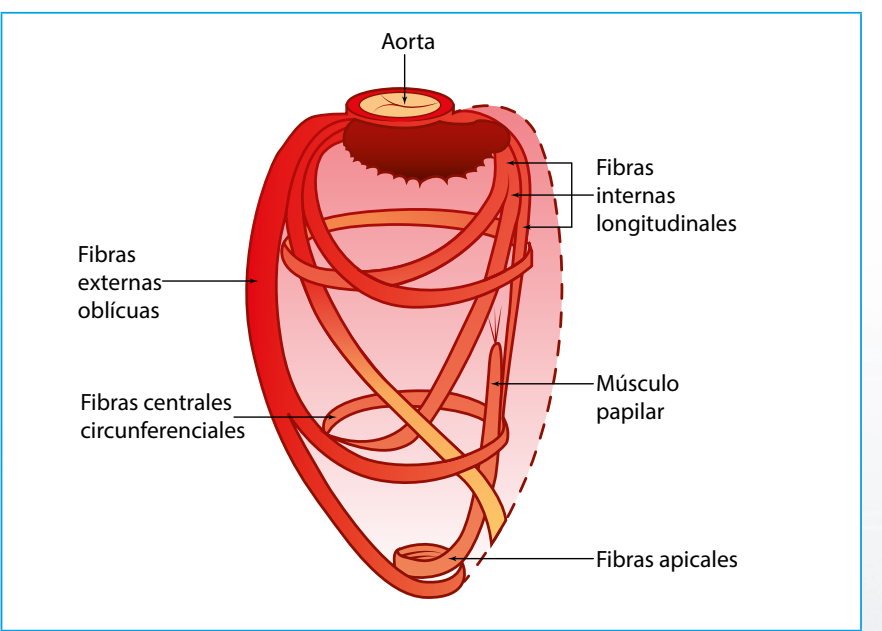

Figura 14. Disposición de las fibras (ventrículo izquierdo) ${ }^{(10)}$

Con las técnicas de speckle tracking se confirma la presencia de una leve deformación postsistólica normal en el ventrículo izquierdo, su distribución y la relación temporal con la contracción activa en el periodo isovolumétrico diastólico del ventrículo izquierdo, como mecanismo íntimo y responsable de la succión, concluyendo que los segmentos con mayor porcentaje de registro de deformación postsistólica se corresponden anatómicamente con la porción ascendente de la lazada apical de la banda miocárdica ${ }^{(11)}$.

El estudio del strain longitudinal y circunferencial mediante speckle tracking, así como de la torsión ventricular, permite dar soporte a la distribución anatómica de la banda muscular. La deformación radial, resultante de todas las fuerzas que interactúan, es mayor a nivel basal y medial por la prevalencia de fibras transversales, mientras que las fibras oblicuas de la lazada apical hacia el ápex son responsables de una mayor deformación longitudinal y circunferencial con predominancia de la rotación apical ${ }^{(12)}$.

La rotación del ápex tiene sentido antihorario, visto desde la punta; mientras que la base presenta una rotación horaria contrapuesta. El torque o radio de rotación del subepicardio es mayor que el del subendocardio, por tanto, el subepicardio provee una mayor fuerza de rotación que el subendocardio y, como resultado, la rotación del subepicardio se expresa más significativamente a nivel apical. Hay que comprender que la rotación se produce por la contracción de las fibras helicoidales, y la intensidad y dirección están dadas por el balance de las fibras subendocárdicas y subepicárdicas.

La determinación de la torsión miocárdica es de crucial importancia, ya que la información puede llegar a considerarse más fidedigna que la clase funcional o la fracción de eyección y transformarse en un predictor eficaz en diferentes escenarios de la patología cardiovascular, fundamentalmente en el periodo inicial y/o subclínico de la insuficiencia cardíaca.

Recientemente, se ha propuesto la utilización de nuevos índices ecocardiográficos que evalúen todos los componentes de la compleja arquitectura miocárdica. Así, el parámetro combinado de deformación incluye: el producto de deformación (Giro x Strain Logitudinal [0 x \%]), y el índice de deformación (Giro/SL [0 / \%]). El producto de deformación informa de la función miocárdica global (longitudinal y rotacional) y puede estar normal o disminuido. El índice de deformación advierte sobre el o los componentes afectados y el grado de participación de cada uno de ellos, así como de su posible interacción compensatoria(13).

Por último, la evaluación del flujo de sangre mediante el estudio de los vórtices es otro nuevo paradigma del análisis de la función cardíaca, consecuencia de la torsión miocárdica ${ }^{(14)}$. Su estudio cualitativo y, fundamentalmente cuantitativo, mediante la evaluación de los speckles sanguíneos, va a ser una realidad en la ecocardiografía Doppler con aplicación clínica en un futuro cercano.

\section{Bibliografía}

1. Shaner RF. On the muscular architecture of the vertebrate ventricle. J Anat 1923; 58: 59-70.

2. Torrent Guasp F. La estructuración macroscópica del miocardio ventricular. Rev Esp Cardiol 1980; 33: 265-287.

3. Trainini JC, Elencwajg B, López-Cabanillas N, et al. Ventricular torsion and cardiac suction effect: The electrophysiological analysis of the cardiac band muscle. Interventional Cardiol 2017; 9 (1): 45-51.

4. Carreras F, Ballester M, Pujadas S, et al. Morphological and functional evidences of the helical heart from non-invasive cardiac imaging. Eur $J$ Cardiothoracic Surg 2006; 29 (Suppl 1): S50-55.

5. Trainini JC, Elencwajg B, López-Cabanillas N, et al. Electrophysiological Bases of Torsión and Suction in the Continuous Cardiac Band Model. Anat Physiol 2015; 5: S4-001.

6. Ballester M, Ferreira A, Carreras F. The myocardial band. Heart Fail Clin 2008; 4 (3): 261-272.

7. Trainini JC, Lowenstein J, Beraudo M, et al. Myocardial Torsion. Ed. Biblos, Bs. As, 2019.

8. Anderson R, Ho S, Redman K, et al. The anatomical arrangement of the myocardial cells making up the ventricular mass. Eur J Cardiothoracic Surg 2005; 28: 517-525.

9. Poveda F, Gil D, Martí E, et al. Estudio tractográfico de la anatomía helicoidal del miocardio ventricular mediante resonancia magnética por tensor de difusión. Rev Esp Cardiol 2013; 66: 782-790.

10. Sengupta PP, Krishnamoorthy VK, Korinek J, et al. Left ventricular form and function revisited: applied translational science to cardiovascular ultrasound imaging. J Am Soc Echocardiogr 2007; 20: 539-551.

11. Mora V, Roldán I, Romero E, et al. Myocardial contraction during the diastolic isovolumetric perior: analysis of longitudinal strain by means of speckle tracking echocardiography. J Cardiovasc Dev Dis 2018; 5: 41.

12. Mora Llabata V, Roldán Torresa I, Saurí Ortiza A, et al. Correspondence of myocardial strain with Torrent-Guasp's theory. Contributions of new echocardiographic parameters. Rev Arg de Cardiol 2016; 84: 541-549.

13. Romero Dorta E, Mora Llabata V, Roldán Torres I, et al. Propuesta de un nuevo parámetro para la estimación de la función miocárdica a partir del strain ventricular. Rev Esp Cardiol 2017; 70 (Supl 1): 409.

14. Trainini J, Elencwajg B, López Cabanillas N, et al. Stimulus Propagation and Left Ventricular Torsion. Advancements in Cardiovascular Researc 2018; 1 (2): ID.000109. 